\title{
Coronary Vessel Lesion
}

National Cancer Institute

\section{Source}

National Cancer Institute. Coronary Vessel Lesion. NCI Thesaurus. Code C100063.

Pathologic material in a vessel that obstructs myocardial perfusion. (ACC) 